\title{
E-BRIEF
}

September 6, 2017

\section{Closing the Divide: Progress and Challenges in Adult Skills Development among Indigenous Peoples}

by

Parisa Mahboubi and Colin Busby

- Skills gaps between off-reserve Indigenous people - First Nations, Métis and Inuit - and non-Indigenous Canadians are wide among those without a high-school education - a gap compounded by relatively high dropout rates among Indigenous youth.

- Skills gaps are largest in northern communities, the western provinces and in Ontario.

- What is to blame? Identifiable socioeconomic factors collectively account for over half of the skills gap between Indigenous and non-Indigenous populations. In particular, differences in education levels and the characteristics of the home environment explain the largest share of this gap.

- Skills gaps shrink among those with a high-school education and close further with higher levels of education. Improving gaps in educational attainment should be a part of efforts to reduce skills gaps, especially when it comes to establishing foundational skills in primary and secondary education.

A thriving Canada must see everyone benefit from economic progress. This means ensuring a prosperous future for Indigenous people. Presently, Indigenous people are less likely to attain higher levels of education relative to non-Indigenous Canadians and the unemployment rate among

The authors thank Benjamin Dachis, Marc Frenette, members of the Human Capital Policy Council and anonymous reviewers for comments on an earlier draft. The authors retain responsibility for any errors and the views expressed. 
working-age Indigenous people is over one-and-a-half times the rate among non-Indigenous Canadians. Broadly speaking, lower educational attainment among Indigenous people contributes to labour market disadvantages (Jankowski and Moazzami 1995; Halchuk 2006), but more specifically, cognitive skills obtained during one's education explain much variation in employment and wages, especially among those in the workforce with similar education credentials. Literacy and numeracy skills are foundational for on-the-job performance: higher levels of literacy and numeracy skills are associated with higher employment rates and earnings (e.g., Hanushek et al. 2013; Statistics Canada et al. 2013).

This E-Brief highlights some shortcomings and successes in skills development for Indigenous people relative to non-Indigenous Canadians from the 2012 Programme for the International Assessment of Adult Competencies (PIAAC) - a major international survey on adult skills. ${ }^{1}$ The PIAAC survey is a unique information source on working-age skills, especially for Canada, because it provides a rich picture of skills development in the labour force on a regional basis. Further, with large samples of immigrants and off-reserve Indigenous people, which include First Nations, Métis and Inuit, we can analyse the performance of a number of critical populations. ${ }^{2}$

To preview the central findings, the skills and labour market outcomes of Indigenous people show that literacy skills gaps are mainly driven through differences in level of education - many other causes are not identifiable using PIAAC data. Further, PIACC highlights the need to better understand why some provinces - and some Indigenous people - are doing better than others.

\section{Assessing the Skills Gaps}

Employment and workforce participation rates are indicators of labour market success. In the Canadian PIAAC sample, 76 percent of non-Indigenous respondents were employed when the survey was conducted compared to 65 percent of Indigenous people. Withdrawal from the labour force was substantially higher among Indigenous people - 27 percent of all people in the sample - relative to 19 percent of non-Indigenous Canadians. Further, Indigenous unemployment rates were over one-and-a-half times greater than those of non-Indigenous people.

In all three domains of PIAAC results - literacy, numeracy and problem solving in technology-rich environments - Indigenous people, on average, scored less than non-Indigenous Canadians (Table 1). ${ }^{3}$ The gaps between Indigenous and non-Indigenous people are large in literacy as well as in numeracy: Indigenous people

1 The 2012 Programme for the International Assessment of Adult Competencies measured proficiencies in literacy, numeracy, and technology usage skills (problem solving in technology-rich environments) on a scale of 0-500. Its Canadian data sample included identifiers for vulnerable sub-populations such as immigrants and Indigenous people, which allows us to compare skill levels between Indigenous and non-Indigenous Canadians. However, we distinguish between immigrants and non-Indigenous Canadians as the performances of immigrants in the PIAAC because the latter are usually not reflective of outcomes from Canadian educational institutions.

2 Each province and territory was responsible for regional oversamples, and most paid for an Indigenous oversample with the exception of Alberta, Québec and the Atlantic Provinces.

3 We have extracted the immigrant population from the comparator group in non-Indigenous Canadians. For accurate estimations, we used all 10 plausible values for each skill as well as the final weight and its 80 replicate weights in this study. 


\begin{tabular}{|c|c|c|c|c|}
\hline $\begin{array}{l}\text { Population } \\
\text { Categories }\end{array}$ & Literacy & Numeracy & $\begin{array}{l}\text { Problem Solving } \\
\text { (in a Technology- } \\
\text { Rich Setting) }\end{array}$ & $\begin{array}{c}\text { Percentage of University } \\
\text { Educated People within } \\
\text { each Sub-Population in } \\
\text { the PIAAC Sample } \\
\text { (percnet) }\end{array}$ \\
\hline Non-Indigenous & 280 & 272 & 286 & 22 \\
\hline Indigenous & 260 & 244 & 274 & 10 \\
\hline First Nations & 253 & 235 & 270 & 9 \\
\hline Metis & 272 & 259 & 280 & 13 \\
\hline Inuit & 218 & 199 & 248 & 4 \\
\hline \multicolumn{5}{|c|}{ Note: The scale is out of 500 . } \\
\hline
\end{tabular}

scored 20 points lower in literacy and 28 points lower in numeracy. ${ }^{4}$ The poor performances of Indigenous people relative to non-Indigenous Canadians in the PIAAC results are mainly a reflection of the highest level of education achieved: in PIAAC, only 10 percent of Indigenous Canadians held a university degree compared to 22 percent of non-Indigenous Canadians (Table 1). Among Indigenous people, Inuit performed poorly in all three domains and only 4 percent had a university education. In contrast, Métis performed substantially better than First Nations and Inuit and had smaller skills gaps relative to non-Indigenous people.

Although literacy proficiency increases alongside educational attainment for both Indigenous and nonIndigenous populations, literacy skills vary among those with similar education levels (Figure 1A). Importantly, the gap in literacy scores between Indigenous and non-Indigenous population shrinks, but does not fully close, with more education: ${ }^{5}$ among those who have an education below high school, Indigenous people score 18 points lower than non-Indigenous Canadians. But the negative skill gap reduces to 10 points - a big drop among those with high school and falls further to 8 points among college and university graduates. Hence, Indigenous people start to catch up to the rest of the population in terms of skill development upon completion of high school and even more so after post-secondary education (PSE).

Among Indigenous groups, literacy gaps also vary across education levels (Figure 1B). However, Indigenous groups at any education level had a very poor performance in literacy relative to similarly educated nonIndigenous people, with the exception of Métis. The literacy gaps are substantially larger among Inuit and First Nations with an education below high school. The skill gaps among those who have not completed high school

4 The literacy, numeracy and technology-use skills are highly correlated in the PIAAC, resulting in analogous conclusions for each skill. Due to similarity in the outcomes, we only report the results of literacy skills for the remainder of this paper.

5 The same trends are also observed with numeracy test scores. 


\section{Figure 1A: PIAAC Results of the Literacy Gaps between Indigenous and Non-Indigenous by Levels of Education}

Gap in Literacy Score (Points)

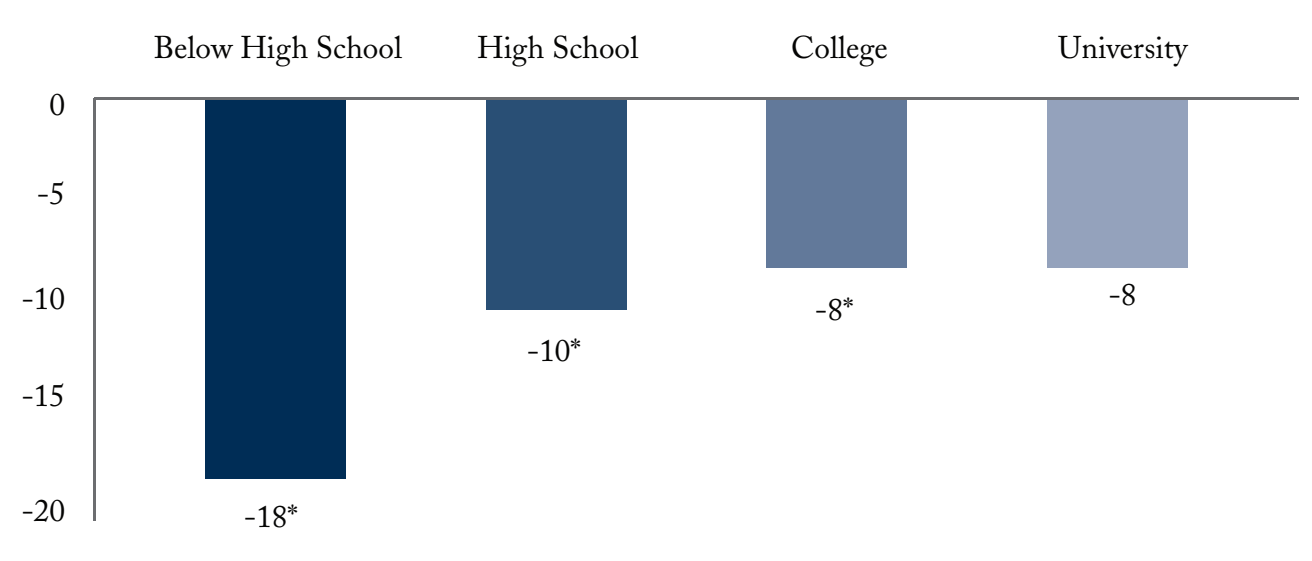

Figure 1B: Literacy Gaps between Indigenous and Non-Indigenous by Indigenous Group and Education Level

Gap in Literacy Score (Points)

- Below High School $\quad$ High School College University

First Nations Métis Inuit

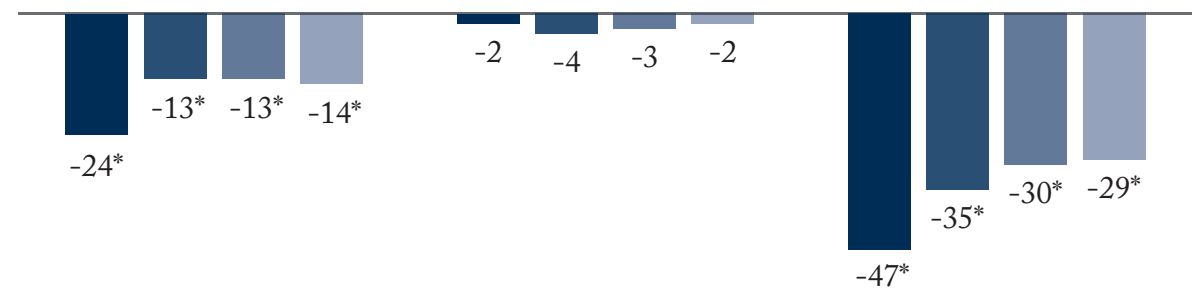

Note: Immigrants are excluded from non-Indigenous.

* Denotes statistical significance from zero with 95 percent confidence.

raise serious concerns. The dropout rate among Indigenous people is substantially higher than that for nonIndigenous Canadians (Anderson and Richards 2016), further compounding the broader skills challenges in the labour market.

The variations in the skills gap between Indigenous and the rest of the population is not only related to levels of education. There is also substantial variation among those with the same level of education across the regions in Canada. The PIAAC survey captures off-reserve, mainly urban Indigenous people, meaning that, even when taking into account migration, the provincial and territorial results should be partly reflective of different approaches to Indigenous education. 


\section{Figure 2: PIAAC Results for Below-High-School Educated Population Sub-Groups by} Region of Residence

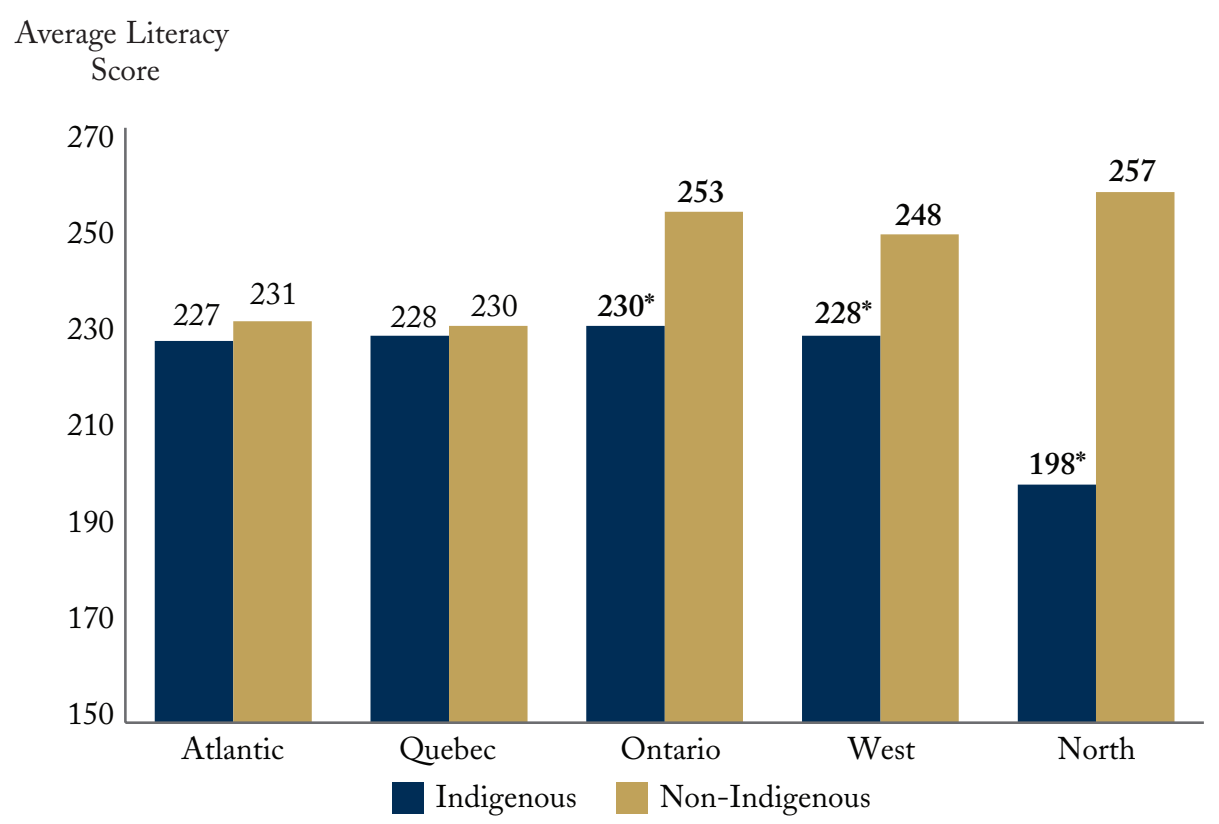

Note: Bold numbers and* signs in Figure 2 represents the statistically significant differences with 99 percent confidence in average literacy scores between the population categories within each region.

On this score, there is no substantial gap among those without a high-school education in the Atlantic region or Quebec (Figure 2). The significant gap in national average literacy scores is driven by those who have no high-school degree in Ontario, the western provinces and in the territories. Among the university educated, the statistically significant gap between Indigenous and non-Indigenous in Ontario and the West disappears, but remains for Inuit in the North.

PIAAC also contains information about workers in different age groups, including those under age 24, and in 10 -year cohorts up to age 64. With these data we can explore whether younger cohorts see similar skills gaps as, for example, those who graduated from high school 10 years ago. Using a straightforward regression analysis, in which we look at skills gaps across age groups and control for education levels, language and location, the skills gaps of recent graduates do not appear to be narrowing relative to graduates from a decade prior (Table 2). ${ }^{6}$

Skills gaps are large among First Nations and Inuit across all age groups, and skills gaps are small among younger Métis, while disappearing among older workers. The large skills gaps between younger workers could

6 For the PIAAC Public use microdata file (PUMF), several variables were deleted from the microdata file or transformed into the less informative categorical variables such as region of residence or earnings, which limit the regression analysis. 


\begin{tabular}{|c|c|c|c|c|c|}
\hline \multirow{2}{*}{$\begin{array}{c}\text { Population } \\
\text { Groups }\end{array}$} & \multicolumn{5}{|c|}{ Age Groups } \\
\hline & $<24$ & $25-34$ & $35-44$ & $45-54$ & $55+$ \\
\hline First Nations & $-16^{* * *}$ & $-12^{* *}$ & $-9^{* *}$ & $-14^{* * * *}$ & $-12^{* * *}$ \\
\hline Métis & -7 & -3 & 3 & -2 & -2 \\
\hline Inuit & $-38^{* * *}$ & $-32^{* *}$ & -14 & $-28^{* * *}$ & $-30^{*}$ \\
\hline \multicolumn{6}{|c|}{$\begin{array}{l}\text { Note: The dependent variable is the literacy scores in the PIAAC; control variables include education levels, language, } \\
\text { parental education, gender, and location; regression coefficients are relative to non-Indigenous and non- immigrant people; *** } \\
\text { significant with } 99 \text { percent confidence; ** significant with } 95 \text { percent confidence; * significant at } 90 \text { percent confidence. }\end{array}$} \\
\hline
\end{tabular}

have to do with different preferences for staying in formal education, but nonetheless we think that, given pockets of progress in provincial school boards, it would be more encouraging were the skills-gap results shrinking among younger generations.

\section{What Factors Help Explain the Gaps?}

The PIAAC survey contains an individual's environmental circumstances that could influence skill acquisition. Factors that impact the process of acquiring cognitive skills include education, age, work experience, parental education, and region of residence. ${ }^{7}$ By taking these elements into account, we can observe the extent to which they explain the gaps. Using a common approach to parsing out the demographic characteristics in the data (see Frenette 2008), we find that 53 percent of the significant negative gap in average literacy scores between Indigenous and non-Indigenous people is explained by differences in socioeconomic factors listed in Table $3 \mathrm{a}$ or Table $3 \mathrm{~b}^{8}$

Education gaps between Indigenous and non-Indigenous peoples account for 41 percent of the skills gap in literacy, followed by factors linked to the home environment (15 percent), such as books in the home and parental education. However, a large proportion of the skills gap between Indigenous and non-Indigenous people remains unexplained, or can be perhaps be attributable to school environment factors. ${ }^{9}$ Negative numbers in Table $3 \mathrm{a}$ and $3 \mathrm{~b}$ - like those that result from the relatively younger Indigenous population - reduces the overall, average skills gaps.

There are notable variations in skills gaps among Indigenous groups (Table 3a) and across regions Table 3b), with small gaps in the Atlantic region and among Métis, and much larger ones in the North and among Inuit.

7 Other factors include whether one's mother tongue is the same as the test language, and the number of books at home by the age of 16 .

8 We applied the Blinder-0axaca decomposition technique and used the pooled coefficients. The choice of using Indigenous or non-Indigenous coefficients as weights did not substantively alter the results.

9 We are unable to control for these factors due to PIAAC's limitations in collecting these types of information. 
Table 3a: Factors Influencing the Skills Gaps between Indigenous and Non-Indigenous Adults, Broken Down by Indigenous Group (Percent of Total Gap)

\begin{tabular}{l|c|ccc}
\multicolumn{1}{c|}{ Variable } & All & \multicolumn{3}{c}{ By Indigenous Group } \\
& & First & Metis & Inuit \\
\hline Education & 41 & 34 & 69 & 29 \\
\hline $\begin{array}{l}\text { Home Environment (parental education and } \\
\text { number of books in the home) }\end{array}$ & 15 & 14 & 20 & 14 \\
\hline $\begin{array}{l}\text { General Demographic Characteristics (age, gender } \\
\text { and language) }\end{array}$ & -4 & -3 & -7 & -1 \\
\hline Work Experience & 2 & 2 & 2 & 1 \\
\hline Region & -2 & -2 & -13 & 3 \\
\hline Total Explained Gap & 53 & 44 & 70 & 46 \\
\hline Unexplained Gap & 47 & 56 & 30 & 54 \\
\hline
\end{tabular}

Table 3b: Factors Influencing the Skills Gaps between Indigenous and non-Indigenous Adults, Broken Down by Region (Percent of Total Gap)

\begin{tabular}{|c|c|c|c|c|c|c|}
\hline \multirow{2}{*}{ Variable } & \multirow{2}{*}{ All } & \multicolumn{5}{|c|}{ By Region } \\
\hline & & Atlantic & Quebec & Ontario & West & North \\
\hline Education & 41 & 48 & 47 & 28 & 39 & 33 \\
\hline $\begin{array}{l}\text { Home Environment (parental } \\
\text { education and number of books } \\
\text { in the home) }\end{array}$ & 15 & 27 & 14 & 22 & 14 & 25 \\
\hline $\begin{array}{l}\text { General Demographic } \\
\text { Characteristics (age, gender } \\
\text { and language) }\end{array}$ & -4 & 7 & 12 & -1 & -6 & 0 \\
\hline Work Experience & 2 & 0 & -4 & 0 & -1 & 6 \\
\hline Region & -2 & - & - & - & - & - \\
\hline Total Explained Gap & 53 & 82 & 69 & 50 & 46 & 63 \\
\hline Unexplained Gap & 47 & 18 & 31 & 50 & 54 & 37 \\
\hline
\end{tabular}


There are also variations in the effects of major individual factors, such as education and home environment, which explain the skills gap. In particular, improvement in educational attainment of Métis accounts for 69 percent of the skills gap while among Inuit and First Nations, education only accounts for 29 percent and 34 percent of the gap, respectively. Educational attainment also plays a major role in Quebec and the Atlantic province and a much smaller role in Ontario.

\section{Conclusion: Improving and Tracking Progress in Workforce Skills}

The PIAAC results reveal key facts about skills development among Canada's Indigenous people. The nationwide performance of Indigenous people in literacy and numeracy skills is mainly affected by the greater number of individuals with incomplete high school. Indigenous people without high-school completion experience substantially lower test scores in literacy and numeracy compared to non-Indigenous high-school dropouts, particularly in certain regions, such as the West, Ontario and the Territories.

Success in reducing the skills gaps will, to some degree, require greater educational attainment among Indigenous peoples, including higher rates of high-school completion and better access to, and persistence in, post-secondary education. As is often mentioned, improvements in the quality of Indigenous education require special attention to the main components of the educational framework, including teachers, principals and the curriculum (Waubageshig 2016), and in how school administrators and provinces work with First Nations. In this vein, there are lessons to learn from different provincial approaches to Indigenous education in primary/ secondary and postsecondary programs (Richards 2013).

With a few notable exceptions, Canadian governments collect very little data that identify the success of Indigenous students in primary and secondary schools. ${ }^{\mathbf{1 0}}$ Even the OECD's Program for International Student Assessment (PISA), which is a standardized test administered to 15-year olds in a number of countries and provinces, does not identify the performance of Indigenous students. British Columbia is rare in that it collects and publishes data that track the performance of Indigenous students in provincial schools. Yet other overarching reasons to monitor Indigenous student outcomes are institutional ones: they should help educators and administrators better understand the causes for differences in - and focus attention on - student outcomes to guide improvement (Anderson and Richards 2016).

Going forward, the PIAAC survey should be a critical input into measuring our ability, as a society, to ensure more inclusive economic growth. ${ }^{11}$ More detailed data could also help provide a better understanding of different approaches and policy recommendations. However, even though PIACC allows us to evaluate foundational skills among adults, the focus of policymakers should be on developing these skills during primary and secondary education - without them, catching up in one's adulthood is a much greater challenge. Policymakers and communities in Canada must prioritize educational outcomes and workforce skills development to improve the prospects for Indigenous people.

10 Using linked datasets in the Youth in Transition Survey, researchers found that PISA reading scores and school marks help explain much, but not all, of the differences in university attendance between Indigenous and non-Indigenous students (Frenette 2010).

11 The precursor to the 2012 PIAAC, namely the 2003 International Adult Literacy Skills Survey, also helped illustrate some important literacy performance challenges among working-age Indigenous people in Canada (Biswal 2008). 


\section{References}

Anderson, Barry, and John Richards. 2016. Students in Jeopardy: An Agenda for Improving Results in BandOperated Schools. Commentary 444. Toronto: C.D. Howe Institute. January.

Frenette, Marc. 2008. "Why are Youth from Lower-income Families Less Likely to Attend University? Evidence from Academic Abilities, Parental Influences, and Financial Constraints." Chapter in Who Goes? Who Stays? What Matters: Accessing and Persisting in Post-secondary Education in Canada. Eds. Ross Finnie, Richard E. Mueller, Arthur Sweetman and Alex Usher.

Frenette, Marc. 2010. "What Explains the Educational Attainment Gap between Aboriginal and NonAboriginal Youth?" Chapter in Pursuing Higher Education in Canada: Economic, Social and Policy Dimensions. Eds. Ross Finnie, Marc Frenette, Richard E. Mueller and Arthur Sweetman.

Jankowski, Witold, and Bakhtiar Moazzami.1995 "Returns of Education among Northwestern Ontario's Native People." Canadian Journal of Native Studies, 15(1): 104-111. January.

Halchuk, Pauline. 2006. "Measuring Employment Outcomes for Indigenous Australians.” Australian Journal of Labour Economics, 9(2): 201-2015. June.

Hanushek, Eric A., Guido Schwerdt, Simon Wiederhold, and Ludger Woessmann. 2013. "Returns to Skills Around the World: Evidence from PIAAC.”NBER Working Paper No. 19762. Cambridge, MA. The National Bureau of Economic Research.

Richards, John. 2013. Why is BC Best? The Role of Provincial and Reserve School Systems in Explaining Aboriginal Student Performance. Commentary 390. Toronto: C.D. Howe Institute. October.

Statistics Canada, Employment and Social Development Canada, and Council of Ministers of Education, Canada. 2013. "Skills in Canada: First Results from the Programme for the International Assessment of Adult Competencies (PIAAC).” Statistics Canada Catalogue no. 89-555-X.Ottawa.

Waubageshig, 2016. "First Nations Elementary-Secondary Education: A National Dilemma." Verbatim. Toronto: C.D. Howe Institute. June.

Biswal, Bagala. 2008. "Literacy Performance of Working-age Aboriginal people in Canada: Findings Based on the International Adult Literacy and Skills Survey (IALLS) 2003.” Human Resources and Skills Development Canada.

This E-Brief is a publication of the C.D. Howe Institute.

Parisa Mahboubi is Senior Policy Analyst, C.D. Howe Institute.

Colin Busby is Associate Director, Research, at the C.D. Howe Institute.

This E-Brief is available at www.cdhowe.org.

Permission is granted to reprint this text if the content is not altered and proper attribution is provided. 